\title{
A Critical Appraisal of Grice’s Cooperative Principle
}

\author{
Atefeh Hadi \\ School of Languages, Cultures \& Linguistics, Monash University, Melbourne, Australia \\ Email: atefeh.hadi@monash.edu
}

Received November $4^{\text {th }}$, 2012; revised December $10^{\text {th }}$, 2012; accepted December $17^{\text {th }}, 2012$

\begin{abstract}
Grice's most influential contribution to linguistics is his theory of implicatures. He describes communication as adhering to what he calls the Cooperative Principle (CP) and argues that a basic underlying assumption we make when we speak to one another is that we are trying to cooperate to construct meaningful conversations (1975). Grice's Cooperative Principle has been a central and controversial theme in pragmatics. A major source of controversy associated with the $\mathrm{CP}$ is that the term "cooperation" is open to different interpretations. In order to develop a thorough understanding of the concept, the CP and conversational implicatures should be studied within the context of Grice's work. The present article is an attempt to critically examine various representations and interpretations of Grice’s Cooperative Principle.
\end{abstract}

Keywords: Grice’s Maxims; Cooperative Principle; Pragmatics

\section{Introduction}

In pragmatics, the major aim of communication is considered the exchange of information. People usually cooperate to convey their intentions and implicit import of their utterances. Therefore, all things being equal conversations are cooperative attempts based on a common ground and pursuing a shared purpose.

Grice's work on the Cooperative Principle led to the development of "pragmatics" as a separate discipline within linguistics. However, the interpretation of the CP is sometimes problematic because Grice's technical term “cooperation” is often confused with the general meaning of the word cooperation.

It should be stressed here that what is centrally important to Grice is the concept of rationality and it is for this reason he discusses cooperation. Most linguists, on the other hand, are interested in the operation of the CP in language use and (flouts, violations, infringing, and opting out) and only a few of them introduce the concept of rationality in relation to the CP into their discussion. Grice considers his maxims as examples of principles, not rules.

Grice first introduces the Cooperative Principle and explained conversational implicature in his article, "Logic and Conversation” (1975). He argued the generation and perception of these implicatures was based on the following principle: "Make your conversational contribution such as is required, at the stage at which is occurs, by the accepted purpose or direction of the talk exchange in which you are engaged" (Grice, 1975: p. 48). Put more simply, the Cooperative Principle attempts to make explicit certain rational principles observed by people when they converse.

Grice claims that human beings communicate with each other in a logical and rational way, and cooperation is embedded into people's conversations Furthermore he argues, this habit will never be lost, because it has been learned during their childhood. Here, the point is that audience listener understands the implication of a speaker's remarks by drawing on an assumption of cooperativeness, contextual information and background knowledge.
In his theory, Grice makes a distinction between saying and meaning. He argues that speakers can create the implicit meanings and their audiences are able to infer these intended meaning from their conversations. He believes that people follow certain patterns in their interactions and claims that listeners generally assume that a speaker's utterance contains enough information, and is relevant. When it patently violates this assumption, we understand that meaning. Therefore, violation of relevance does not mean a lack of cooperation.

Grice considers the coherence or unity of conversations at a rational level, i.e. the rational structure of a conversation. He is concerned with the ways in which we connect our sentences meaningfully in a conversation and the reasons for saying what we do. Considering people's interaction, particularly when different speakers try to promote various issues, it can be clearly seen that their conversation enjoys partial unity (Brown and Yule, 1983: pp. 88-89), but it seems that Grice have an ideal king in his mind.

\section{Grice’s Maxims}

In order to explain the processes underlying implication, Grice (1975) developed the following maxims:

- Quality: speaker tells the truth or provable by adequate evidence;

- Quantity: speaker is as informative as required;

- Relation: response is relevant to topic of discussion;

- Manner: speaker avoids ambiguity or obscurity, is direct and straightforward.

These maxims do not prescribe how one should talk, but explain the listeners' assumptions regarding the way speakers do talk. Bach (2005) believes that Grice introduced these maxims as instructions for successful communication. He thinks that they are better understood as presumptions about utterances, presumptions that listeners count on and speakers use.

Davies (2008) says that when the surface meaning of an utterance does not follow the Gricean maxims (but the circumstances show that the speaker is complying with the Cooperative Principle) we should go beyond the surface to find the 
implied meaning of the utterance.

Grice points out examples of implicatures or three categories of cases in which a maxim is flouted, clashed or violated. In the first case, the speaker cannot accomplish the maxim due to certain effect. In a clash of maxims, the speaker is not able to complete the maxim in order to respect the listeners, and in the last case, there is hidden non-cooperation and the speaker can be misled (Grice, 1989: p. 30). In all of these cases, Grice believes that the audience assumes the speaker is cooperating, following and respecting the maxims.

Some authors have questioned Grice's conversational maxims. For example, Horn (1984) identified only three maxims, and Sperber and Wilson (1986) ignored the structure of maxims and focused on the notion of relevance.

\section{Logic and Conversation}

Grice (1975) is interested in the concept of logic and the relationship between conversation and logic. He considers logic a basic philosophical tool, but claims that the formal devices that indicate the logical functions of and, or, and so forth, have different meaning from their natural language equivalents. Then, he summarizes the formalists and non-formalists positions regarding this issue as follows. Formalists believe that the additional meanings within natural language are flaws of that system, and we should make an ideal language, including the formal devices, and clear and explicit sentences without any metaphysical implications. By contrast, the non-formalists state that failing to grasp the meaning of words lacking logical equivalence should not be regarded as a problem in the system: language plays other functions rather than serving science.

Grice argues that the formalists cannot explain the logic of conversation. He adds that they acknowledge existence of these divergences, but claims they are mistakes which stem from an insufficient attention given to the nature and importance of the conditions that govern conversation.

To challenge this viewpoint, Grice (1975) tries to prove the operation of logic in the performance of these aspects of conversations. To him, implicatures are used as an instrument to investigate and signal the philosophical usefulness of implicatures, and to indicate that it is possible for us to systematically explain structures that ignore the understanding of formal logic.

\section{Kinds of Cooperation}

Many scholars make distinctions between different kinds of cooperation in order to limit the scope of Grice's Cooperative Principle. For example, Pavlidou (1991: p. 12) differentiate between formal cooperation and substantial cooperation. In her words, formal cooperation is just like "cooperation in the Gricean tradition, i.e. acting according to the conversational maxims (or against them).” however, substantial cooperation refers to "sharing common goals among communication partners, goals that go beyond maximal exchange of information." This distinction sounds similar to the distinction between linguistic and extra-linguistic goals.

Others used different terminologies to distinguish between a broader and a narrower notion of cooperation and their associated goals. Gu (1999) makes a distinction between "communicative and extra-communicative goals”. Thomas (1986) distinguishes between the "social goal sharing interpretation of cooperation" and the arguably meaningless concept of "linguistic cooperation”. Sarangi and Slembrouck (1992) argue that we should be cautious when distinguishing between linguistic and social goal sharing cooperation.

Lumsden (2008) claims that there are two kinds of cooperation: "social" and "linguistic or formal" cooperation. He provides a narrower definition for the notion of cooperation (linguistic cooperation), and tries to apply Grice's principle only to that. But there seems to be a problem with this broader goal, because when we have cooperation with a broader goal, this goal sounds to specify relevance in the conversation.

However, the broad strategy can be beneficial in describing Grice's Cooperative Principle. Such a distinction is useful and acceptable, because it represents that when we do not have extra-linguistic cooperation, we can rely on merely linguistic cooperation (Lumsden, 2008).

\section{Critical Challenges to Grice's Theory}

Grice's Cooperative Principle has played a historically important role in pragmatics, because this theory separated pragmatics from linguistics. However, the interpretation of his theory is problematic. There seems to be a misinterpretation between everyday notion of “cooperation”, and Grice’s technical term.

Thomas (1998b: p. 176) argues that proponents of Grice's theory have neglected to explore the ambiguous term "cooperation" and have not explained how they interpreted and used this concept in their own works. She adds many authors have criticized Grice's theory due to misunderstanding about the misleading term “cooperation”. Ladegaard (2008) explains that because of the ambiguity of and inconsistency within Grice's own definition of "cooperation" those adopting this theory often define this term to suit their own purposes.

Davies (2007) argues that opposing interpretations of the "cooperation" notion originate from the conflict between Grice's use of this term with a technical meaning, and the more general meaning of the word. It is not a term that is repeated in Grice's thought, and is not the central force in his analysis of the workings of language. Applying these two interpretations to the same field creates confusions among linguists. It seems that the Cooperative Principle deals with a meaning closer to the general meaning of “cooperation” (Davies, 2007).

Some researchers claim that Grice's Cooperative Principle and its maxims are universal. For example, Green (1996) argues that rationality and cooperativeness are characteristics common to all the speakers in the world; therefore, non-cooperative conversations should be regarded as cooperative considering more global themes including listener and speaker (p. 98). Cappella (1995) also mentions that rejecting the cooperative principle as a norm may lead to inefficient and unfinished interactions. But in fact Grice never explicitly stated that his theory had universal application; so, it is a wrong assumption among these scholars.

Thomas (1998a) criticizes Grice's theory for three misinterpretations which are as follows: viewing human nature optimistically, proposing a series of rules for effective conversation and believing that his suggested maxims would always be taken into consideration. Thomas (1998a, 1998b) claims that although Grice's theory is not satisfactory and suffers from a lot of holes, nothing better has been found to replace it.

Taillard (2004: p. 247) attacks Grice's claim that people normally cooperate and follow the maxims, and mentions that 
"Human communication rests on a tension between the goals of communicators and audiences". In fact, he believes that we, as communicators, interact to fulfill our benefit and interest, but it does not mean that we always tell the truth.

Sarangi and Slembrouck (1992) also criticized the Gricean claim for the normality of cooperation. They applied a Gricean pragmatic approach to institutional discourse and suggested that Grice's framework should be extended to include societal factors such as the social position of the communicators. They said, "If we are to follow the Gricean notion of cooperation, the institution, in such circumstances, would be expected to adopt, at least from the client's point of view the client's goal as its own, or act towards negotiating a 'mutually accepted goal'."

Thus many researchers have questioned or rejected the universality as well as the feasibility of Grice's cooperative principle. Grice's theory is too biased towards the notion of cooperation in human conversation. But he cannot answer questions about what would happen in situations where human beings prefer employing non-cooperative strategies; or how the cooperative principle accounts for miscommunication.

\section{Comments on Grice's Theory}

In his article, Ladegaard (2008) suggests that both the semantic and the pragmatic sides of human interaction as well as all the linguistic awareness necessary for the perception and interpretation of meaning in any communicative behavior should be covered in any theory of conversational cooperation.

He argues that Grice only considers the semantic aspect of an utterance and then makes it clear based on pragmatics, or according to the context which help us to interpret the speaker's intentions.

Gumperz (1982) argues that it is necessary for the speakers to take into account all the contextual clues which exist in various discourse types. These include turn-taking strategies, speech accommodation, and voice alterations. Ladegaard (2008) also adds that in order to understand the intention of speaker accurately in an interaction, and interpret the underlying meaning of an utterance, the use of these cues is really essential.

Ladegaard (2008) states that instead of applying the traditional view to language and communication offered in Pragmatics, in which human interaction is viewed as naturally deficient and problematic, a broader view should be considered. He mentions that Grice is extremely biased towards cooperation. Grice's assumption is that people communicate logically, and all of them attempt to be "good" communicators.

However, Ladegaard's (2008) analysis conflicts with Grice's position. He claims "human interaction may be irrational and illogical, and that resistance and non cooperation may be adopted as the preferred discursive strategy, and that interactants seem to try their best to be 'bad' communicators."

In his study Ladegaard (2008), considered the two types of cooperation related to a Gricean theory: "social goal-sharing and linguistic goal-sharing”. In this analysis, teachers interview students regarding their future career. The aim is investigating attitude-behaviour relationships in language.

Ladegaard's results show that students' dialogues are noncooperative and non-accommodative, and that these are the preferred discourse strategies used by students. In other words, in their interviews students, try to miscommunicate rather than to communicate successfully. Ladegaard's believes social and psychological conditions determine people's intensions as to whether or not to cooperate in a conversation.

\section{Conclusion}

In summary, Grice's theory is flawed. First, it is too biased towards cooperation. Grice believes that people aims at communicating successfully and effectively and in trying to solve their problems. Actually, he neglected the fact that there are times when the purpose is to intentionally miscommunicate.

Second, his theory is fundamentally asocial. We can say that he follows Chomsky's idea (1965: p. 4), of positing an "ideal speaker-listener in a completely homogeneous speech community." Therefore, he fails to explain how people actually communicate concerning sophisticated social contexts, for instance if speakers aim to be accepted in all social settings in which they find themselves.

Since Grice's theory does not take the social contexts into account, and only considers the speaker-listener interaction in an ideal context, and applies universally (regardless of social elements such as sex, power relationships, social class, and age) it has little explanatory power.

Based on the Cooperative Principle, people are naturally directed towards cooperation. In other words, they often want their interactions to succeed, they want to solve problems and discuss solutions. But, sometimes the purpose is to fail and undermine the conversation, and to be sure that one does not achieve his goal, i.e. to prefer to miscommunicate. As Mey (2001) claims, in flouting a maxim, people are trying to be non-cooperative to indicate their resistance, so the effects they are aiming for should be considered cautiously.

As stated above, Grice is interested in finding the logic of conversation and how we can explain the gap between saying and meaning, saying and implicating, conventional and nonconventional meaning. This logic, in his view, is considered as a manifestation of rational acts.

His theory is inflexible, because it does not consider the fact that human communication like his nature is a complicated, diverse and rich phenomenon. Moreover, it disregards the situations where the interactants's goal is to miscommunicate. As Sarangi and Slembrouch (1992: p. 142) assert:

"A sufficient theory should illustrate how people get the speakers' intention by pointing out the social positioning of the language users and the societal bearings on the situational context."

In conclusion, although being based on introspection rather than data, and does not consider interpersonal factors, Grice's work faces major limitations, it is still at the centre of the disciplines of pragmatics and the important role it plays in this field cannot be denied. However we should be careful interpreting what is meant by “cooperation” in Grice's CP. His notion is different from the everyday notion of cooperation. Some authors make this difference clear to readers. To have a fair understanding of the Grice' CP, it would be better to study it in the context of Grice's works as a whole rather than in isolation.

\section{REFERENCES}

Brown, G., \& Yule, G. (1983). Discourse analysis. Cambridge: Cambridge University Press. doi:10.1017/CBO9780511805226

Davies, B. L. (2008). Grice's cooperative principle: Meaning and rationality. Journal of Pragmatics, 39, 2308-2331. 


\section{A. HADI}

doi:10.1016/j.pragma.2007.09.002

Grice, H. P. (1968). Utterer's meaning, sentence meaning and word meaning. Foundations of Language, 4, 225-242.

Grice, H. P. (1975). Logic and conversation. In P. Cole, \& J. Morgan (Eds.), Syntax and semantics (pp. 41-58). New York: Academic Press.

Grice, H. P. (1989). Studies in the way of words. Cambridge, MA: Harvard University Press.

Ladegaard, H. J. (2008). Pragmatic cooperation revisited: Resistance and non-cooperation as a discursive strategy in asymmetrical discourses. Journal of Pragmatics, in Press.

Lumsden, D. (2008). Kinds of conversational cooperation. Journal of Pragmatics, 40, 1896-1908.

doi:10.1016/j.pragma.2008.03.007

Sarangi, S. K., \& Slembrouk, S. (1992). Non-cooperation in communication: A reassessment of Gricean Pragmatics. Journal of Pragmatics, 17, 117-154. doi:10.1016/0378-2166(92)90037-C 